\title{
Apocrine Carcinoma of the Axilla Associated with Extramammary Paget's Disease: A Case Report and Review of the Literature
}

\author{
Hye Ra Jung · Sun Young Kwon · Daegu Son ${ }^{1}$ \\ Departments of Pathology and ${ }^{1}$ Plastic Surgery, Keimyung University School of Medicine, Daegu, Korea
}

Paget's disease has traditionally been divided into mammary and extramammary. Extramammary Paget's disease (EMPD) most commonly affects the anogenital area, though it can rarely affect the axillae, in which apocrine glands are normally encountered. ${ }^{1}$ Herein, we report a rare case of apocrine carcinoma associated with EMPD of the axilla with review of the relevant literature.

\section{CASE REPORT}

The publication of the case information and materials was approved by the Institutional Review Board of Keimyung University Dongsan Medical Center.

A 77-year-old man was referred with a 3-month history of an erythematous, hyperkeratotic, and inflamed eczematous patch with focal desquamation and itching sensation in the left axilla. Examination of the left axilla showed a discrete red patch with irregular margins and exudative surface, measuring $5 \times 3 \mathrm{~cm}$. No fungal hyphae were noted on the $\mathrm{KOH}$ test. Histological examination of a punch biopsy showed round, pale malignant cells scattered individually and in groups throughout the epidermis, particularly in the basal layer. Also, a focal intradermal invasive lesion was noted. The patient was treated with wide excision with margins up to $2 \mathrm{~cm}$. The cut surface of the resected specimen showed a round, pale, tan to white and solid subcutaneous mass, measuring $0.8 \mathrm{~cm}$ in diameter. The mass was

\section{Corresponding Author}

Hye Ra Jung, MD

Department of Pathology, Keimyung University School of Medicine, 56 Dalseong-ro, Jung-gu, Daegu 41931, Korea

Tel: +82-53-580-3826, Fax: +82-53-250-7211, E-mail: junghr0519@dsmc.or.kr

Received: May 7, 2015 Revised: June 18, 2015

Accepted: June 22, 2015 attached to the overlying skin. Histologically, the subcutaneous mass consisted of large, round to polygonal cells with abundant eosinophilic cytoplasm, indicative of apocrine carcinoma. Some sweat glands in the dermis were filled with malignant cells, similar to those in the subcutaneous mass. These cells also involved the epidermis and showed a typical pagetoid spread. The infiltrative and intraepithelial tumor cells stained positive with periodic acid Schiff and showed strong positive immunohistochemical staining for cytokeratin 7 (CK7) and HER2, confirming the diagnosis of invasive apocrine carcinoma with EMPD (Fig. 1). The tumor cells showed focal and weak positivity for anti-gross cystic disease fluid protein-15 (GCDFP-15) and were negative for GATA-3, estrogen receptor, and progesterone receptor.

Based on these results, the patient was evaluated for evidence of breast cancer to rule out metastatic apocrine carcinoma from the breast. Chest radiograph and breast ultrasonogram showed no definite lesion. After 6 months of follow-up, the patient is healthy and free of symptoms.

\section{DISCUSSION}

Paget's disease is an intraepithelial neoplastic lesion involving Paget cells, which are regarded as apocrine origin because of their immunohistochemical characteristics; positive staining for carcinoembryonic antigen, GCDFP-15, and CK7. ${ }^{2}$

In rare cases, Paget's disease co-exists with underlying invasive apocrine carcinoma. EMPD with underlying invasive apocrine carcinoma in the axilla is rarer. Morgan $e t ~ a l .^{3}$ reported a case of axillary EMPD with underlying apocrine carcinoma. They reported that $45.5 \%$ (5/11) of previously reported axillary EMPDs were associated with an underlying carcinoma. ${ }^{3}$ Chiu $e t$ 

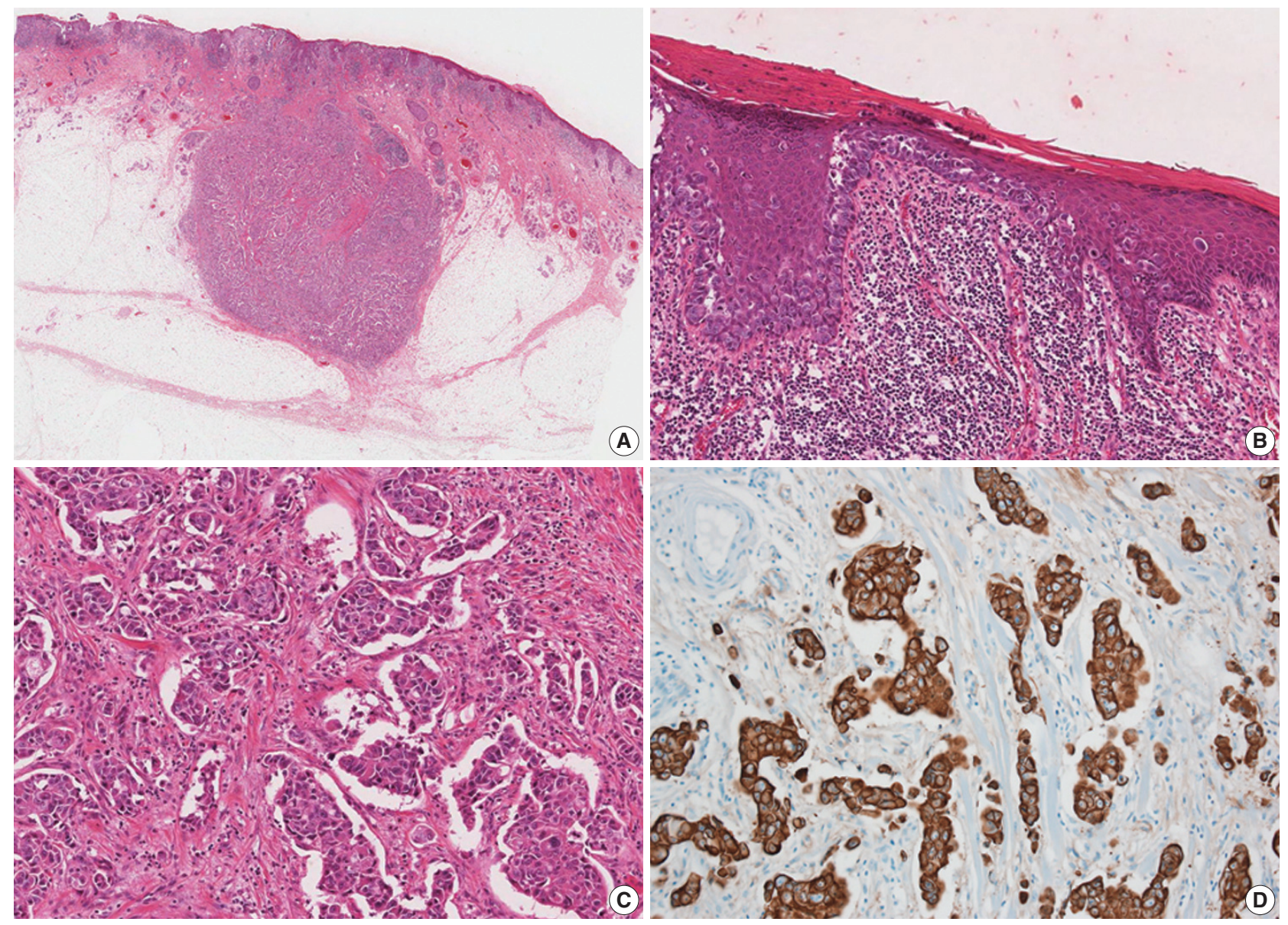

Fig. 1. (A) Slide scan of the left axillary lesion shows a round mass in the subcutaneous tissue. (B) Large tumor cells with abundant cytoplasm show a pagetoid spread pattern in the epidermis. (C) Tumor cells with abundant eosinophilic cytoplasm infiltrating the dermis. (D) Tumor cells showing diffuse strong positive staining for cytokeratin 7 .

$a l .^{4}$ reported seven cases of EMPD in the unilateral axilla, with only one patient having underlying adnexal carcinoma (14.3\%).

Wilkinson and Brown ${ }^{5}$ classified vulvar EMPD into intraepithelial Paget's disease, intraepithelial Paget's disease with invasion (IP), and intraepithelial Paget's disease with underlying adenocarcinoma (IEPUA). Based on Wilkinson and Brown's classification, the present case was thought to be IEPUA. In other studies of EMPD in the vulvar region, IEPUA represents between $2 \%$ and $37 \%$ of all cases. ${ }^{6-9}$ Kodama et al. ${ }^{8}$ reported a recurrence rate of $79.8 \%$ and a survival rate of $27.7 \%$ for patients with IEPUA. Parker et al. ${ }^{9}$ have similarly reported poor prognosis for patients with IP and IEPUA. ${ }^{7}$ However, in the report of Chiu et al., ${ }^{4}$ no patient experienced recurrence after surgery (mean time of follow-up, 65.7 months) even in the cases of underlying malignancy (i.e., at least IP or IEPUA). All patients in their study underwent local wide excision with margins up to $2-3 \mathrm{~cm}$. The authors offer that the low recurrence rate of patients in their study might be a result of the clear anatomy of the axillary region compared with that of the anogenital area, the early stages of their cases, and the limited follow-up.

When apocrine carcinoma is present in the axilla, metastasis from breast apocrine carcinoma or primary breast cancer in ectopic mammary tissue must be ruled out. Immunohistochemistry is not helpful in differentiating these options. ${ }^{10}$ In apocrine carcinoma of ectopic mammary tissue, remaining ectopic mammary tissue is present in the sample. To exclude the possibility of metastatic mammary apocrine carcinoma, additional breast examination and radiologic work-up are needed. In the present case, there was no evidence of apocrine carcinoma arising in ectopic mammary tissue or of metastatic mammary apocrine carcinoma.

We report a rare case of EMPD with underlying invasive apocrine carcinoma in the axilla in order to increase awareness of EMPD in the axilla and to highlight its association at this site with adjacent underlying apocrine carcinoma. 


\section{Conflicts of Interest}

No potential conflict of interest relevant to this article was reported.

\section{REFERENCES}

1. Elder DE, Elenitsas R, Johnson BL Jr, Murphy GF, Xu G. Lever's histopathology of the skin. Philadelphia: Lippincott Williams \& Wilkins, 2009.

2. Merot Y, Mazoujian G, Pinkus G, Momtaz TK, Murphy GF. Extramammary Paget's disease of the perianal and perineal regions: evidence of apocrine derivation. Arch Dermatol 1985; 121: 750-2.

3. Morgan JM, Carmichael AJ, Ritchie C. Extramammary Paget's disease of the axilla with an underlying apocrine carcinoma. Acta Derm Venereol 1996; 76: 173-4.

4. Chiu CS, Yang CH, Chen CH. Extramammary Paget's disease of the unilateral axilla: a review of seven cases in a 20-year experience. Int J Dermatol 2011; 50: 157-60.
5. Wilkinson EJ, Brown HM. Vulvar Paget disease of urothelial origin: a report of three cases and a proposed classification of vulvar Paget disease. Hum Pathol 2002; 33: 549-54.

6. Shaco-Levy R, Bean SM, Vollmer RT, et al. Paget disease of the vulva: a histologic study of 56 cases correlating pathologic features and disease course. Int J Gynecol Pathol 2010; 29: 69-78.

7. Jones IS, Crandon A, Sanday K. Paget's disease of the vulva: diagnosis and follow-up key to management; a retrospective study of 50 cases from Queensland. Gynecol Oncol 2011; 122: 42-4.

8. Kodama S, Kaneko T, Saito M, Yoshiya N, Honma S, Tanaka K. A clinicopathologic study of 30 patients with Paget's disease of the vulva. Gynecol Oncol 1995; 56: 63-70.

9. Parker LP, Parker JR, Bodurka-Bevers D, et al. Paget's disease of the vulva: pathology, pattern of involvement, and prognosis. Gynecol Oncol 2000; 77: 183-9.

10. Toledo-Pastrana T, Llombart-Cussac B, Traves-Zapata V, et al. Case report: differential diagnosis between primary cutaneous apocrine adenocarcinoma versus extramammary or metastatic breast adenocarcinoma. Am J Dermatopathol 2014; 36: e175-8. 